\title{
Fiscal and Monetary Policy of Economic Development
}

\author{
By Igor Chugunov ${ }^{1}$, Mykola Pasichnyi ${ }^{2}$, Valeriy Koroviy ${ }^{3}$, Tetiana Kaneva ${ }^{4}$, \\ Andriy Nikitishin ${ }^{5}$
}

\begin{abstract}
Fiscal and monetary policy coordination should focus on increasing public welfare and maintaining long-term macroeconomic stability. This article aims to enhance the theoretical and methodological basis of fiscal and monetary policy formation and determine the priority areas for improving their coordination to ensure sustainable economic development. We developed an institutional approach to study the fiscal-monetary mix. It is advisable to create favorable monetary conditions for fiscal measures and form a balanced budget for monetary regulation. The authors proposed the structuralfunctional model that highlights both fiscal and monetary policies' impact on aggregate demand. The results showed no positive effects of general government expenditures on the GDP per capita growth in 19 emerging economies from 1995 to 2018. The influence of public spending on economic growth depends on institutions' quality, the composition of expenditures, and fiscal architecture. The expediency of increasing the share of productive expenditures that positively affect stimulating the economy is substantiated. In the long-run, monetary policy should ensure a comprehensive combination of inflation targeting conditions, the adaptive use of tools to achieve intermediate and final targets.
\end{abstract}

Keywords: fiscal policy, monetary policy, budget, taxes, economic development.

\section{Introduction}

Fiscal and monetary policies' coordination forms the key prerequisite for macroeconomic stability and sustainable economic growth. Moreover, the leading social and economic development objectives are practically unachievable through the monistic application of fiscal or monetary regulation in the long-run. Over a relatively extended period, fiscal dominance or monetarism formed the basis for the development policy in advanced economies. The practical experience confirmed the reasonableness of those scientific concepts' convergence in close interaction between fiscal and monetary policy, especially in a recession. Those policies' insufficient coherence leads to significant destructive economic consequences. Well-coordinated fiscal and monetary regulation measures combined with low quality of institutions deteriorate the public financial policy's efficiency. It is essential to apply them harmoniously and complexly, analyzing the relevant causal relationships. Exercising their functional powers, fiscal and monetary institutions have crucially different goals. However, the central economic policy aims to increase public welfare and is familiar to all public policy elements.

\footnotetext{
| ${ }^{1}$ Head of Department of Finance, Kyiv National University of Trade and Economics, Ukraine

${ }^{2}$ Department of Finance, Kyiv National University of Trade and Economics, Ukraine

${ }^{3}$ Kyiv National University of Trade and Economics, Ukraine

${ }^{4}$ Faculty of Finance and Accounting, Kyiv National University of Trade and Economics, Ukraine

${ }_{5}^{5}$ Department of Finance, Vinnytsia Institute of Trade and Economics of Kyiv National University of Trade and Economics, Ukraine
} 
Fiscal and monetary institutional tools have dissimilar inherent nature and impact on business entities' activity and aggregate demand. The institutional independence in the financial policy measures' preparation increases its validity, based on various economic theories. The powers' redistribution amid the authorities enables to represent significantly different institutional approaches to the financial levers' and instruments' impact on the economy and determine the principal risks and threats for macroeconomic stability. Fiscal targets should not significantly undermine price stability, while the excellent monetary regulator's control should not provoke a recession. Both fiscal and monetary authorities should be coordinated over the medium-term to reduce the agents' uncertainty and the key macroeconomic indicators' volatility. Significant attention should be paid to the relevant instrument's duration, nature, and lag effects. Specific institutional and operating arrangements might support the coordination of fiscal and monetary policies.

\section{Literature Review}

Arestis (2015) pointed out that fiscal policy was a useful tool for macroeconomic stabilization, especially in close coordination between monetary policy and the other government financial regulation measures in the field of financial stability. Simionescu et al. (2017) found that budget expenditures on education and research generally correlated with the real GDP growth rate, but their impact depended on the national financial policies' peculiarities. Afonso and Furceri (2010) empirically studied the fiscal instruments' impact on economic processes. They concluded that, with an increase in the share of government revenues in GDP, the simultaneous decrease in real GDP per capita in the OECD countries occurred. Chugunov et al. (2018) studied the fiscal policy instruments' impact on economic growth and social development. Authors found that expansionary fiscal adjustments based on government revenues cuts and spending increases were more effective than entirely based on spending increases. Significant fiscal consolidation includes the government's primary spending reduction.

Mishchenko and Lon (2017) argued that specific monetary preconditions' creation is the main task for promoting economic development. Those preconditions were: macroeconomic stability, the banking system's credibility, the general budget's balance, the low public debt level, and slow and relatively stable inflation. Annicchiarico and Rossi (2013) highlighted that - applying inflation targeting strategy - the central bank reduced the general uncertainty and essentially contributed to economic growth. Mollick et al. (2011) analyzed a sample of 22 advanced and 33 emerging market economies. They proved that the real GDP per capita growth was accelerated when fully-fledged inflation targeting has been adopted. Reynard (2007) noted that focusing on the low inflation targets disregarding the relevant monetary aggregate targets could lead to excessive monetary restrictions, limiting the real GDP growth potential. Lagutin (2017) proved that fiscal and monetary policy coordination with its inherent anti-inflationary direction should encourage economic growth. He highlighted that government economic policy's main effects should reduce the volatility of the economic growth's main economic parameters. Lukianenko and Dadashova (2016) investigated interconnections between the National Bank and the government regulation of the economy and distinguished seven phases in monetary and fiscal policy interconnections. 
There is a need to investigate further the regulatory financial mechanisms' impact on economic development regarding the actual conditions. It is expedient to improve the institutional framework for the fiscal and monetary policies' interaction to ensure the longrun macroeconomic stability and the fundamental prerequisites for sustainable economic growth.

The paper aims to enhance the theoretical and methodological basis of fiscal and monetary policy formation and determine the priority areas for improving their coordination to ensure sustainable economic development.

\section{Results}

The government permanently improved the assessment of fiscal and monetary policies' coordination efficiency. Inflation is one of the essential investigated policies' interaction indicators; price stability is a measuring criterion for the regulation's efficiency. Regarding the partly fiscal nature of the inflation dynamics, it is impossible to connect the full responsibility for price stability with the central bank's actions. The public authorities' intentions to accelerate economic growth and stimulate aggregated demand through fiscal tools are reflected in the governmental monetary policy. In emerging market economies, fiscal policy has a crucial impact on inflation. The budget expenditures' regulation intensifies inflation; that fact is coherent with the increased aggregate demand. On the other hand, the tax policy's impact on the consumer price index is not so distinct: an increase in the tax burden on consumption accelerates inflation; the prices may rise if income taxes increase. Hence, both fiscal and monetary measures should reduce inflation's volatility to the optimal values, considering the national economic model.

Commodity economies have slightly higher inflation than advanced and technologically diversified ones. The average CPI in Brazil from 2003 to 2018 was 6.32 \%, in Kazakhstan $-8.23 \%$, in India $-6.78 \%$, in the Russian Federation $-9.16 \%$, and in the EU $-1.84 \%$, respectively. Public financial policy components' interaction efficiency hugely depends on the institutional environment's quality. Commodity economies traditionally have insufficient institutional development and populism (while the public financial policy is applied). Venezuelan experience characterized by the highest in the world inflation rate in the postwar period proves the above statement. In advanced economies, to refine fiscal discipline, the improvements in monetary rules and the respective policy's modernizations are automatically associated with certain budget restrictions. To foster economic growth, both financial regulation measures' impact-factors and their public presentation significantly matter. Monetary and fiscal policies' measures are simultaneously targeted to increase public welfare and maintain long-term macroeconomic stability. Significant socioeconomic indicators' volatility, their crucial vulnerability to the exogenous shocks, and the high degree of development's uncertainty deteriorate output growth. Fiscal and monetary policies' coordination should be focused on the respective goals' dialectical unity.

Regarding economic sustainability, price stability - in the form of low and stable inflation - is practically reachable only through the coordinated interaction of public financial measures. The gradual reduction in the CPI level and volatility accomplished by the structural modifications in the area related to the expansion in the tax base and public expenditure optimization affects the slowdown of government size growth. Nominal 
budget revenues and expenditures increased by $43.00 \%$ and $29.98 \%$ in 2015 compared to the previous year. In 2016 it increased by $20.06 \%$ and $22.92 \%$; in $2017-$ by $29.89 \%$ and $26.47 \%$, in 2018 - by $16.47 \%$ and $18.30 \%$, and in 2019 - by $8.91 \%$ and $9.59 \%$, respectively. Economic growth enables to adapt the inherent fiscal system's institutional architectonics, aiming to increase the overall resources efficiency. The budget funds' effectiveness and rational use significantly matter to optimize the expenditures' structure considering the consumer goals' proclamation and the investment demand stimulation. In emerging market economies, a sharp boost in public spending does not affect the rise in their productive component due to low fiscal policy's capacity to generate economic development incentives. Regarding the long-term budget planning, the key budget indicators' relatively moderate growth rate reduces the fiscal mechanism's impact on the increased prices.

We examined the relationship between public spending and the real GDP per capita growth in the sample of 19 emerging economies over the 1995-2018 period. Although some of the observed the EU member-states are now advanced economies, in the mid1990 s and the early 2000s, they belonged to the group of developing countries. We founded no positive relationship between the increase in public expenditures and the output growth rate. An endogenous general government expenditure increase of 1 percent of GDP declined real GDP by roughly 0.08 percent. The determination coefficient $\mathrm{R}^{2}$ (0.432) is insufficient to sustain the high density between the variables mentioned above. With its public spending-to-GDP ratio exceeding $43.00 \%$ (Figuge 1), Poland had undoubtedly higher economic growth rates than most of the sampled countries because of the carried out structural reforms that permanently improved the institutional environment. Progressive changes in the economy and social sphere have proved the crucial effect. Belarus also demonstrated a higher economic growth rate than most observed countries; nevertheless, the public expenditure ratio-to-GDP is tremendous. It was primarily due to the exogenous financial support, which had created competitive advantages for specific economic sectors and the rational foreign economic policies to promote goods both to the post-Soviet and the EU-markets. Belarus made only a slight correction of its economic model and the de facto command-and-control system's extension.

Chugunov et al. (2019) proved that in Ukraine over the 2001-2018 period, the public debt ratio-to-GDP was mainly affected by monetary factors (e. g., inflation, and the exchange rate). Thus, debt sustainability is enormously dependent on the fiscal and monetary coordination. Even though the safe public debt-to-GDP ratio is equal to $60.0 \%$ according to the Budget Code, emerging economies' experience empirically demonstrated that the above ratio should be reduced to $45.0 \%$. The safe public debt is managed by a consistent and balanced fiscal policy's implementation with a low and stable inflation rate. Hence, 'inflationary erosion' should be avoided.

Dynamic equilibrium should be maintained through the endogenous factors' sustainable economic development, including financial ones. Monetary and fiscal instruments' adaptive combination and interaction and institutional architectonics' improvements intensify business activity both in the national economies' innovative and traditional sectors. Otherwise, significant risks of price and financial instability occur. 


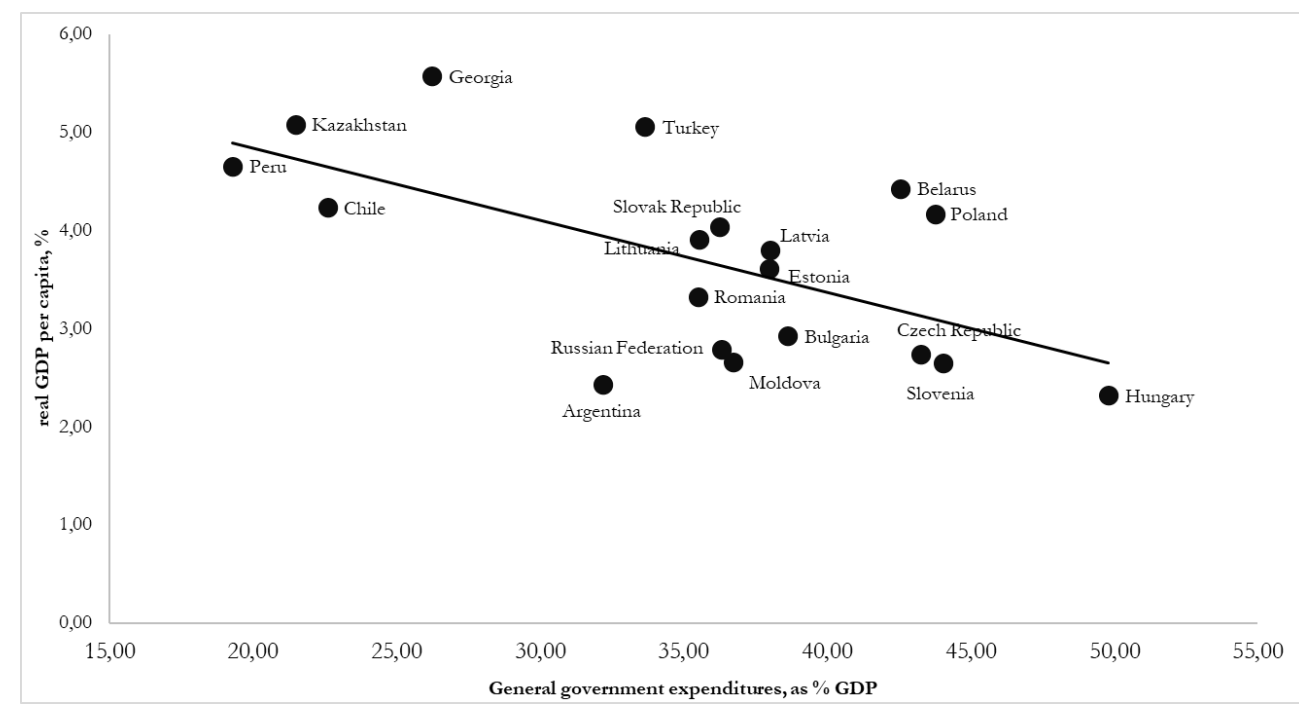

Figure. 1. General government expenditure and the real GDP per growth in emerging economies over the 19952018 period, $\%$

Source: based on the IMF and the World Bank data

There are several configuration options for fiscal and monetary policies' interaction. In particular, one of the policies, as mentioned above, could be considered as dominant. We observed monetary policy instruments' domination. In that case, certain restrictions in fiscal space should be imposed, and the key policy rate should be regulated to maintain the safe public debt-to-GDP ratio. In the case of fiscal policy instruments' domination, no rules for changing the key interest rate in response to the increase in the public debt-toGDP ratio are set. It is also possible to implement passive monetary and fiscal policies. In that case, an increase in public spending is complemented by a parallel increase in public revenues in the form of a balanced-budget increase; the key interest rate is regulated only in response to the price level changes. The last scenario involves the simultaneous implementation of active monetary and fiscal policies. In such circumstances, the central bank focuses on achieving price stability, while fiscal institutions do not react sharply to the public debt-to-GDP ratio's situational fluctuation. Meanwhile, fiscal institutions retain functional powers to conduct counter-cyclical measures in case of justified need.

The central bank can carry out monetary expansion while the central government maintains and intensifies economic growth. Budget expenditures have a significantly different impact on real GDP dynamics. That is due to the balance between productive and unproductive public spending, the quality of fiscal institutions, and the GDP redistribution level through the budget system. Thus, fiscal policy essentially affects the macroeconomic process.

The actual consumer inflation is affected by several factors, including monetary. The latter is directly controlled by the central bank, even if fiscal stimuli were not implemented. Fiscal and other non-monetary factors influence inflation as well. Public financial policy is crucially dependent on the economic agents' expectations. The agents link a significant increase in the deficit and budget expenditures - while fiscal expansion measures are 
implemented - with accelerated consumer inflation in the future, especially in emerging economies. The central bank regulates the key interest rate aiming to stabilize and reduce inflation. As a result, business activity is restrained. Excessive restrictions can lead to a decline in economic growth and public revenues. Fiscal authorities involve some additional government borrowing; consequently, public debt rises. The above situation forms a systemic risk to price stability under limited access to external credit resources and insufficient domestic government borrowing market's development. Thus, to prevent debt instability, fiscal stimuli should be coordinated with monetary policy. The economic environment's variability, the budget planning system's imperfection, and the existing intentions to increase social spending lead to frequent changes in the main budgetary parameters. That fact complicates the interaction between fiscal and monetary institutions. It is expedient to expand the central and local budgets' planning horizon and to impose restrictions on the main budget indicators. Inflation targeting involves a medium-term perspective. Extensive coordination between fiscal and monetary policies makes it advisable to adopt the three-year budget planning. Public expenditures are divided into short-term and long-term (medium-term) components (formula 1):

$\exp _{i}=\exp _{i}^{s h_{-} t}+\exp _{i}^{l_{-} t}$

where

$\exp _{i}$ - public expenditures over the $i$-th budget period;

$\exp _{i}^{s h_{-} t}$ - public expenditures' short-term component;

$\exp _{i}^{l_{-} t}-$ public expenditures' long-term (medium-term);

The long-term component includes budget expenditures associated with substantial economic, social, scientific, defense programs, etc. Their full implementation in the shortrun is impossible. So, the above exclusively requires long-term budget planning with periodic adjustment under changes in the macroeconomic environment. The long-term public expenditures are generally predictable and relatively stable over the planning period. Lawmakers should make an exemption for debt service expenditures, enormously dependent on the national currency exchange rate. In the case of a significant external borrowings' share in the overall debt structure, it is vital to avoid sharp fluctuations in the rate above due to the speculative demand. Artificially pegged exchange rate provokes some fundamental problems (e.g., increased negative trade balance, excessive consumer demand for imported goods, reduced international reserves, etc.). Hence, the flexible exchange rate's expediency is justified. Moreover, the preconditions for fully-fledged inflation targeting adoption are: 1) the flexible exchange rate; 2) the balance of payments' regulation (its devaluation minimizes the current account deficit); 3) both debt sustainability and the budget deficit financing. The government debt accumulation leads to increased debt service payments, debt burden expectations, and deficit, forming a financial sector restrictions system.

The public expenditures' short-term component reflects targeted central executive bodies' response to the cyclical changes in economic growth dynamics, primarily aimed to stimulate aggregate demand. In the long-run, the above indexes fluctuations are significantly higher than the short-term. The expenditures mentioned above' dynamics are closely related to the indicators of current and projected deviations in the GDP gap. The balance between the consumption and investment demand's incentives is the main 
principle for short-term expenditures preparation. The Great Recession crucially impacted the development and interaction concepts between fiscal and monetary policies in advanced economies. For instance: the EU, the USA, and Japan, etc. The tight coordination between financial measures and their focus on impetus creation aimed to restore positive economic dynamics. In the short-run, the public financial policy's priorities were to foster aggregate demand and employment. Responding to the recession challenges, the American Recovery and Reinvestment Act (2009) primarily provided a tax and budget initiatives package equaled to $\$ 787$ billion and then increased to $\$ 831$ billion. Both temporary tax benefits and the taxpayer burden reductions amounted to $34.7 \%$ in the entire fiscal stimuli structure over the period, while the rest related to budget expenditures regulation. The predominant expenditures share was aimed to expand the consumption; nearly $30 \%$ of the increased public spending was directed to the infrastructure's and the public health system's development. The public financial policy's components allowed to maintain price stability for the five years since implementing the American Recovery and Reinvestment Act: the average CPI equaled to $1.60 \%$. Meanwhile, over the 20092013 period, the real annual GDP per capita growth rate was $0.27 \%$.

The expenditures multiplier is an important indicator for assessing the impact of fiscal policy on economic dynamics. The aforementioned financial indicator has a rather complex origin. Firstly, the budget expenditures' compositional structure crucially matters. It is necessary to identify their inherent components characterized by the highest positive effect on economic development. The differentiation of the expenditures in the context of their productivity should consider the respective expenditures ratios to GDP and the general spending. The current fiscal policy's functions and tasks include the public debt service, social stability esurience, budget funding, etc. Secondly, the particular instrument (the tax bases' and rates' expanding, increase in the budget deficit, etc.) - used to finance additional expenditures - significantly matters. Finally, fiscal and monetary policies interconnection's modification affects both the public expenditure multiplier and inflation level. Under conditions of passive monetary policy, both the expenditure multiplier and the consumer price index are significantly high. If the key interest rate is low, especially for advanced economies, the multiplier will be significantly higher than in emerging markets. Another monetary impact-factor on the fiscal stimuli is the exchange rate regime. Under conditions of a pegged exchange rate, the spending multiplier is significantly higher than in the other cases.

Monetary policy has two main objectives depending on the time-scale; in the long-run, the aim is low inflation persistence. In the short- and medium-term, it forms the conditions to foster economic growth. There are principal differences in defining the monetary policy's role at the different business cycle phases. The neoclassical-Keynesian synthesis recommends the central bank to fix the interest rate, while the respective authorities adapt stimuli or consolidation to the cyclical fluctuations. Monetarists argue that the easing policies (aimed to regulate the key interest rate) contribute to the real sector's business activity fluctuations due to the money supply's pro-cyclical changes.

Arestis and Sawyer (2004) concluded that the approach to the monetary policy's regulatory role for economic development has essentially changed over the past decades. Previously, the critical role belonged to the money supply instruments. In current conditions, the central bank's policy possesses a decisive place. The monetary policy's primary goal is to 
achieve price stability, quantified by the relevant medium-term indicator. That policy represents aggregate demand one: a change in the key interest rate impacts aggregate demand and, consequently, inflation. Thus, the monetary policy effectively controls demand-pull inflation.

Price stability is one of the monetary policy's primary goals in most advanced and emerging market economies. Huizinga and Mishkin (1986) pointed out that the relevant policy's methods differed significantly from the chosen monetary regime. An appropriate monetary regime has an essential impact on policy-making, allowing strategic management decisions, and performing operational tasks. The monetary policy's targets are inflation, exchange rate, money supply, and GDP. A discretionary monetary regime exists. It does not apply to the long-term price stability quantitative benchmark. Still, it involves preventive inflation control decisions, regarding primarily the GDP deflator index's manipulations under socio-economic conditions. The central bank should be highly credible and resultative over a long time to apply the above regime. Otherwise, inflation expectations will critically rise, declining the central bank's efficiency.

The reserve requirements hugely impact the money supply, absorbing or increasing liquidity in the banking sector, depending on the economic situation. Thus, credit control affects the dynamics of aggregate demand and GDP. Moreover, the central banks' reserve requirements represent a mechanism to ensure the commercial financial institutions' obligations to their customers, providing financial stability. Hence, significant sanctions are provided for the established reserve requirements' infraction. Open market operations are a universal monetary policy instrument. Buying or selling government bonds, the central bank ensures its operational objectives and maintains a sufficient banking system's liquidity. In advanced economies with a significantly developed financial market, monetary regulation is more flexible and resultative than in emerging. If the central bank owns a large domestic government bond package, the government securities lack of liquidity, significant debt risks, and particular, fiscal imbalance are predictable.

For open economies in the long-run, to ensure adequate financial regulation, monetary policy should combine: a) floating exchange rate (in various modifications), b) inflation targeting, c) adaptive application of institutional instruments (interest rate, monetary aggregates, etc.) to achieve intermediate and final targets. Monetary policy vitally influences macroeconomic dynamics, but the nature of its impact is quite heterogeneous. The issue of assessing the relationship between the exchange rate and GDP or the exchange rate and inflation remains relevant. On the one hand, theoretical statements declare that the national currency's gradual devaluation contributes to strengthening the economy's export potential, simultaneously raising the prices for imported goods. That fact can essentially intensify both the development and implementation of import-substitution programs, accelerating economic growth. Due to the economy's low innovative profile and its inherent commodity nature, the devaluation's positive effect for the exporters is shortterm does not encourage innovations in the real sector. The import-substitution programs are generally short-scaled because the imported goods are mostly complete-cycled and science-intensive ones. Rather significant increase in the technological equipment's costs slows down the domestic enterprises' revitalization, deteriorating their competitiveness. Easterly et al. (1994) profoundly studied the technologies' - primarily borrowed - impact on economic growth and the respective public financial policy's role. Represented by a 
shadow foreign exchange market and double quotes for the different economic agents or the other technology intensification's restrictions, unjustified monetary policy harms economic growth.

The prices - increased due to the domestic market's devaluation - decline the economic agents' purchasing power and aggregate demand and change the structure of consumption with the effect of income redistribution from economic agents with rather high-propensity to the low-propensity ones, declining the macroeconomic indicators. Devaluation with essentially low exports' and imports' price elasticity might deteriorate the trade balance and provoke an economic recession.

Both fiscal and monetary policy measures affecting aggregate demand should be considered in the inseparable unity, taking the financial instruments' interactions into account. We propose a structural and functional model (Figure 2) of fiscal and monetary policies' impact on aggregate demand.

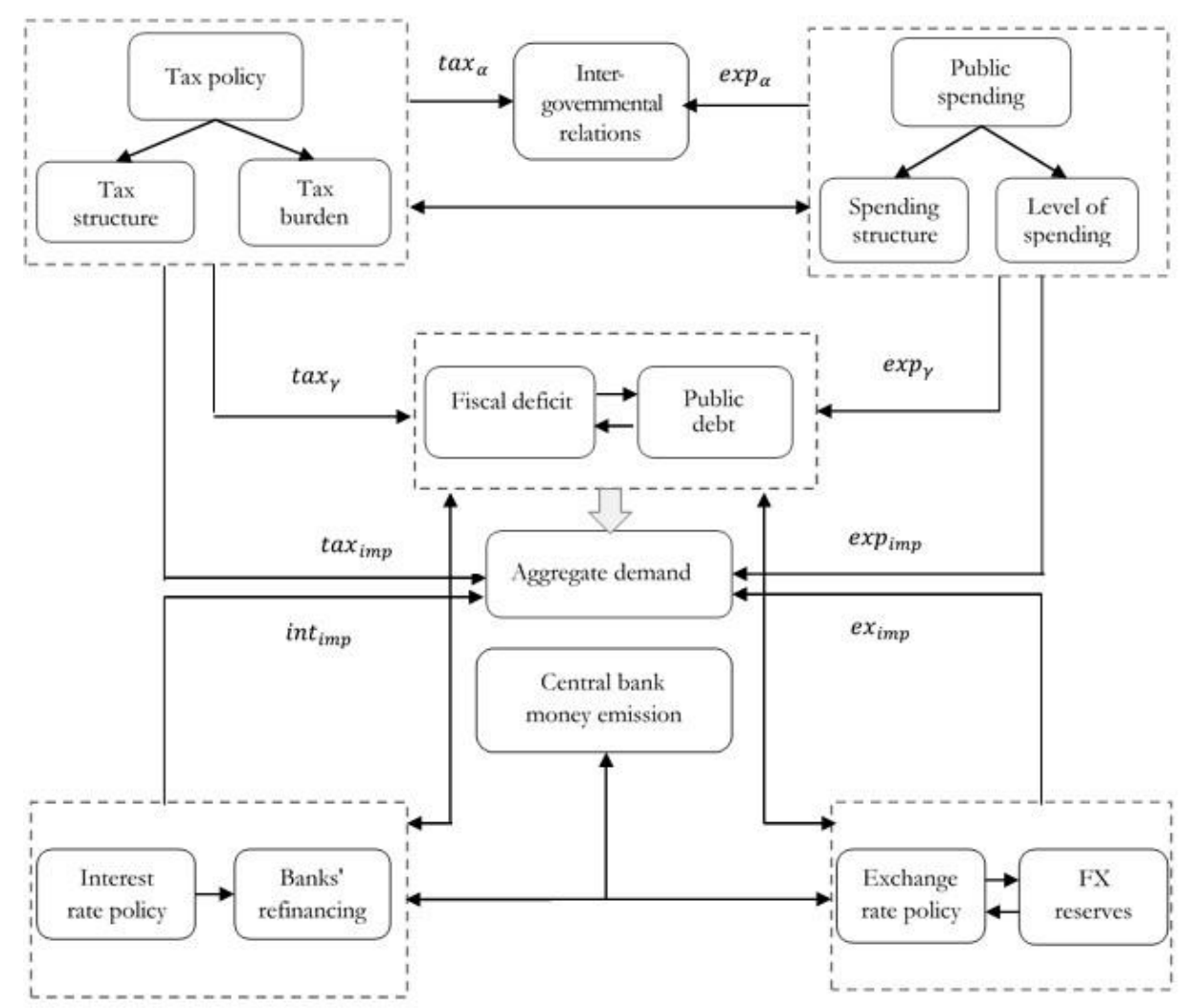

Figure 2. Structural-functional model of fiscal and monetary impact on aggregate demand

where

$\operatorname{tax}_{\alpha}-$ tax policy effects on inter-governmental relations;

$\exp _{\alpha}$ - public spending effects on fiscal decentralization;

$\operatorname{tax}_{\gamma}-$ tax policy effects on the fiscal deficit; 
$\exp _{\gamma}$ - public spending effects on the fiscal deficit and public debt;

tax $_{\text {imp }}$ - tax policy influence on aggregate demand;

$\exp _{\text {imp }}$ - public spending influence on aggregate demand;

int $_{\text {imp }}$ - interest rate policy impact on aggregate demand;

$e x_{i m p}$ - exchange rate policy impact on aggregate demand.

Based on a comprehensive financial instruments combination, that model considers the compositional structure effects, time lags, economic changes, and the financial system's institutional transformations. The model's application allows ensuring the public financial policy's adequacy and adaptability to the economic cycle's relevant stages. It also improves the budget revenues, expenditures, and inter-governmental relations regulation's efficiency, enhances fiscal deficit, and debt management supports both fiscal and monetary policies' coordination.

\section{Conclusions}

The government financial strategy provides variable scenarios for the regulation measures' preparation and implementation based on the macroeconomic trends and objectives at the appropriate social development stage. The prudently coordinated application of fiscal and monetary instruments to maintain macroeconomic stability and enhance its endogenous development factors is appropriate. The modern financial strategy's priorities combine favorable fiscal, monetary, and investment conditions for sustainable economic growth with rational institutional constraints. It is vital to coordinate the central bank's and the fiscal authorities' actions due to the institutional approach, improving their interaction's transparency and efficiency. The powers' devotion allows representing several approaches to the financial instruments' impact on economic development over the long-run. We founded no positive relationship between the increase in public expenditures and the output growth rate. An endogenous general government expenditures increase of 1 percent of GDP declined real GDP by roughly 0.08 percent. The budget system institutional architectonics' functional adaptability should be strengthened to increase government expenditures efficiency and to stimulate investment demand. Both fiscal policy's improved principles in terms of the long-term planning instruments and somewhat moderate key budget indicators reduce the financial mechanism's impact on price dynamics.

Fiscal and monetary policy coordination aims to achieve moderate inflation, maintaining sustainable economic growth, debt sustainability, and balanced public finances. If an active monetary and fiscal policy is implemented, the central bank's activities are focused on ensuring price stability. The fiscal policy's priority is associated with favorable conditions' creation for economic growth through the appropriate regulation of revenues, expenditures, and budget deficit. Depending on the actual conditions and the institutional environment's quality, the government should build financial policy instruments' optimal configuration. In order to intensify economic activity, it is vital to conduct moderate monetary expansion with the implementation of a balanced fiscal policy, except for extraordinary economic cases. 


\section{References}

Afonso, A., \& Furceri, D. (2010). Government size, composition, volatility and economic growth. European Journal of Political Economy, 26 (4), 517-532.

Annicchiarico, B., \& Rossi, L. (2013). Optimal monetary policy in a New Keynesian model with endogenous growth. Journal of Macroeconomics, 38, 274-285.

Arestis, P. (2015). Coordination of fiscal with monetary and financial stability policies can better cure unemployment. Review of Keynesian Economics, 3(2), 233-247.

Arestis, P., \& Sawyer, M. (2004). Can monetary policy affect the real economy?, European Review of Economics and Finance, 3(3), 3-26.

Chugunov, I., \& Pasichnyi, M. (2018). Fiscal stimuli and consolidation in emerging market economies. Investment Management and Financial Innovations, 15 (4), 113-122. doi:10.21511/imfi.15(4).2018.09

Chugunov, I., Pasichnyi, M. \& Nepytaliuk, A. (2019). Macroeconomic effects of inflation targeting in advanced and emerging market economies. Banks and Bank Systems, 14 (4), 153-165. doi:10.21511/bbs.14(4).2019.15

Christiano, L., Eichenbaum, M., \& Rebelo, S. (2011). When is the government spending multiplier large? Journal of Political Economy. 119 (1), 78-121.

Easterly, W., King, R., Levine, R., \& Rebelo, S. (1994). Policy, technology adoption, and growth (No. w4681). National Bureau of Economic Research. Retrieved from https://www.nber.org/papers/w4681.pdf

Hanson, S. G., Stein, J. C. (2015). Monetary policy and long-term real rates. Journal of Financial Economics, 115 (3), 429-448.

Huizinga, J., \& Mishkin, F. S. (1986). Monetary policy regime shifts and the unusual behavior of real interest rates. In Carnegie-Rochester Conference Series on Public Policy. 24, 231-274.

Kalyoncu, H., Seyfettin, A., Tezekici, S., Ozturk, I. (2008). Currency devaluation and output growth: An empirical evidence from OECD countries. International Research Journal of Finance and Economics, 14 (2), 232-238.

Lahutin V. (2017). Economic policy of the state and effects of its realization. Herald of Kyiv national university of trade and economics. 4. 5-20.

Mishchenko V., Naumenkova S., Mishchenko S., Ivanov V. (2018). Inflation and economic growth: the search for a compromise for the Central Bank's monetary policy. Banks and Bank Systems, 13(2), 153-163.

Mishhenko, V. \& Lon, I. (2017). The role of monetary regulation in stimulating economic. Finance of Ukraine. 4. 75-93.

Mollick, A. V., Cabral, R., \& Carneiro, F. G. (2011). Does inflation targeting matter for output growth? Evidence from industrial and emerging economies. Journal of Policy Modeling, 33(4), 537-551.

Lukianenko I. H., Dadashova P. A (2016). Monetary and Fiscal Policies Interaction in Ukraine. Actual problems of economics. 5 (179). 295-307.

Makohon, V., Radionov, Y. \& Adamenko, I. (2020). Investment policy of the state as a tool for economic growth of the country. Problems and Perspectives in Management, 18(3), 245-254. doi:10.21511/ppm.18(3).2020.21

Pasichnyi, M. (2017). Empirical study of the fiscal policy impact on economic growth. Problems and Perspectives in Management, 15(3), 316-322. doi:10.21511/ppm.15(3-2).2017.01

Simionescu, M., Lazányi, K., Sopková, G., Dobeš, K., \& Adam, P. B. (2017). Determinants of Economic Growth in V4 Countries and Romania. Journal of Competitiveness, 8(1), 103-116.

Reynard, S. (2007). Maintaining low inflation: Money, interest rates, and policy stance. Journal of Monetary Economics, 54(5), 1441-1471. 